\title{
Does the economy need political scientists?
}

\author{
Manuela Leitner \\ EGGER Group, St. Johann in Tirol, Austria \\ manuela.leitner@egger.com
}

First of all: Political science is not a vocational study although pretty much every political science student will have heard the question "Oh, so you want to become a politician?" at least once from astonished relatives or acquaintances. At least according to subjective experience, only in very rare cases do young people decide to study political science in order to prepare for a career in a political party or to qualify for a political office. More often, they study political science out of interest. Young people choose to study it because they are interested in political processes, power structures, and influencing factors; because they want to understand better how political systems work, how politics affects society, the individual and, of course, the economy. They also study political science in order to find their place in this interplay of systems, structures and processes with the knowledge acquired there and to be able to make their contribution.

Right after the general assumption that the goal is a political career, the list of most frequent comments turns to, as is probably the case for all humanities and social science studies: "And what do you think you'll do with it later?!" With this we have reached the actual topic. After all, in the vast majority of cases, studies are followed by gainful employment: Can companies make use of the skills of political scientists? And if so, of which ones and to what end?

\section{The economy needs people who are interested in the world around them.}

Young people study political science out of interest, and this is quite important when it comes to analysing its added value for the economy. First and foremost, companies need employees who are interested in the world around them, who are committed, who are passionate about a topic, who want to contribute their ideas and their critical spirit. This usually applies to political sci- entists. This subject is not chosen to achieve anything specific - for example, to become a lawyer or a doctor and be able to afford the Ferrari and the villa.

Political science students aren't careerists who see every service they provide as a means to an end. Rather, they are people who challenge each other intellectually. People with whom one can excitedly discuss in seminars and even all night long about current or historical events and their social impact, about definitions and political theories, about power and power systems, and much more.

In this way, students acquire skills that they can then bring into the corporate environment: They have learned to form their own opinions - and to form this opinion one needs the broadest possible prior knowledge and / or the ability to acquire it as needed. They have learned to defend their opinion in the face of opposition. And they have learned to listen to other opinions as well, to understand other points of view, to weigh them up and finally to make a decision, or, ideally, to reach a balance. Such processes, passion coupled with social skills, are extremely important in business practice to achieve lasting results.

\section{The economy needs people who understand com- plex relationships.}

Political scientists have learned to deal systematically with the three dimensions of political phenomena - polity, politics and policy. So they understand how to create and change rules that are binding on communities and how communities interact with each other. Of course, companies are part of communities - in different ways. Political structures, processes and content influence companies in their business activities. And companies should strive to recruit employees who can systematically observe, analyse, and evaluate these influences. 
What does Brexit mean for an exporting company in the short, medium and long term? How does the political crisis in Ukraine affect business or even employees? How can the interests of a mayor who is about to run for re-election be reconciled with those of the local branch? Are there any new or changed regulations or laws to which business practices need to adapt? Or are there any amendments being planned that could affect the business? And finally: What role does the company play as a member of society?

Business environments and political influences are complex. What is needed there is the ability to understand complex relationships and to network and think analytically. Anyone who has learned to look at topics, questions and problems from different perspectives, to recognise contexts and to filter out erroneous contexts, to draw parallels to other fields of politics and to bring in new perspectives, can apply these abilities in a company and participate in important decision-making processes.

\section{The economy needs people who question motiva- tions.}

Anyone who has completed a degree in political science has probably already from the beginning dealt closely with the term power and the various concepts of power. Without getting lost in definitions: Power is by no means interesting only in the classical political context. In the company itself and in its environment, too, different interests and their enforcement or compensation play a major role. What interests one cares for, and thus puts them on the agenda, how decisions are made and who you are trying to influence can be fundamental to success in all social relationships and, of course, in economic relations.

In the work context, it is important to question and understand the motivations of all actors involved. Only by knowing the relevant interests can one attempt to meet them: with understanding, with a suitable offer, with possibly likewise suitable counter-proposals, with a suggestion for compromise. Only the awareness that we are dealing with different motivations and interests whenever people come together can lead to a reconciliation of interests and thus to achieving results.

Anyone questioning motivations will be able to build an understanding of the target group, understand other strategies, and develop their own strategies. He or she will be able to empathise with others - also by using and analysing data - and thus form robust scenarios for various possible situations. This empathetic as well as strategic thinking political scientists can contribute to companies at least as well as people in other fields of activity.

\section{The economy needs people who think outside the box.}

Political science is a highly interdisciplinary field of study, as reflected in the interdisciplinary lectures and opportunities offered in the curriculum, as well as in the often excessive discussions that take place during classes. In addition to political science, many students also study "adjacent" subjects, such as communication and media studies, business or economics, sociology, or law. A broader knowledge basis makes it possible to understand interdependencies.

In times of digitisation, companies are required to leave their internal comfort zones and work in networks. Anyone who has learned to work flexibly and to seek the best possible solutions for a current research problem beyond departmental or sectorial boundaries has it easy(er) here. Creating a network of trusted persons, informants, supporters, and even friends within the company and in the company environment is not only a generally important social skill, but also indispensable for leading and working in interdisciplinary projects.

In addition, the methodological competencies acquired during the studies enable political scientists to delve into non-industry topics relatively easily and to process them systematically and in a structured manner. In addition, they can, thanks to their intensive theoretical training, handle texts, write texts, do research, and are also good presenters.

Companies are therefore well advised to focus on political scientists for positions with a high degree of networking, flexibility requirements, strategic and analytical tasks, as well as innovation potential. They contribute all these skills and also enrich with their different backgrounds otherwise homogeneous project teams.

\section{Author}

Manuela Leitner has studied political science and communications science and holds a Master's degree in $\mathrm{Eu}$ ropean Politics and Society.

Specialized on organizational communication, she has worked on the agency as well as on the company side. Since 2015, she is Head of Corporate Communications of the EGGER Group and in this position responsible for the strategic communication of the international wood industry company with Tyrolean roots. 